\title{
PSICOLOGÍA POSITIVA: UNA PERSPECTIVA QUE SUPERA EL LÍMITE DE LA ENFERMEDAD MENTAL
}

\author{
Positive psychology: A perspective that exceedes the limit of mental illness \\ Gareth Del Castillo Estrada ${ }^{1, a, \text {, }}$ \\ 1 Escuela profesional de Psicologia, Universidad Andina del Cusco, Cusco, Perú. \\ a Maestro en psicología organizacional \\ $\risingdotseq$ gdelcastilloe@gmail.com
}

Citar como: Del Castillo, G. (2018). Psicología positiva: una perspectiva que supera el límite de la enfermedad mental. Rev Yachay, 7(1), 451-453.

Recibido: 16-09-2018; Aceptado 07-12-2018

\section{Introducción}

Se encuentra consenso al considerar la fecha de inicio de la Psicología Positiva, en el año 1998, cuando Martin Seligman da su discurso inaugural como presidente de la American Psychological Association (APA) (Lupano \& Castro, 2010), desde este momento y hasta la fecha se han evidenciado focalizados intereses en estudios vinculados a la felicidad, actitudes positivas, sentimientos afirmativos, optimismo, valores humanos y demás constructos vinculados a la psicología positiva como eje aglutinador en el estudio del bienestar común y colectivo de las personas, sin significar lo expuesto, el desinterés histórico de la psicología por estos constructos, sino la posibilidad de encontrar una visión aglutinadora de experiencias vinculadas a la felicidad, con un resaltado interés por lo científico.

Es importante, al igual que en la revisión de cualquier aporte al conocimiento, buscar los medios que permitan un adecuado entendimiento del aporte, el mismo que estaría condicionado al contexto temporal y social en su desarrollo. De esta manera encontraremos que la Psicología Positiva, se presenta como una orientación psicológica articulada con el logro del potencial humano, distando de otras orientaciones interesadas únicamente en aportar al entendimiento de procesos psicológicos concretos, hasta aquellas interesadas en establecer miradas condicionadas a un conjunto de factores, para entender al individuo en sus comportamiento y su vinculación con la sociedad en general. Sin embargo, como se podrá comprender, la diversidad de perspectivas vinculadas a la comprensión del objetivo de estudio de la psicología, configuraron un escenario, por lo menos amplio y de entendimiento difuso, pero en ningún momento apartado del análisis del individuo, su manera de actuar y los fenómenos concomitantes a su riqueza de interpretación interna. El mencionado estado multi-enfoque en la comprensión de los fenómenos psicológicos, originaría una defensa recalcitrante de los llamados a representar dichas posturas, así como de sus seguidores, situación que en su dinámica acrecentaría la distancia entre los denominados sistemas psicológicos. Muestra de esta falta de articulación y establecimiento de un objeto de estudio claramente identificado, es la apreciación de Kuhn, dada ya en 1962, al calificar la situación de la psicología como pre-paradigmática bajo la consideración de carecer aun de un paradigma único y aceptado por la mayor parte de sus comunidades (Caparros, 1978), no siendo la psicología positiva una excepción dentro del análisis, pues sus postulados básicos, si bien parten de otros alcances propios de sistemas psicológicos como el humanismo, no deja de ser en realidad una refrescante orientación no alineada claramente a una corriente concreta.

Por otro lado y, como objetivo de análisis del presente trabajo, debemos considerar la poco afortunada ubicación de la psicología dentro de las ciencias de la salud, por lo menos en sus comienzos, situación que, a todas luces, se presenta como desfavorable para una ciencia que goza de amplitud de vertientes interpretativas, así como de campos de acción. Lupano \& Castro en 2010, identifican que antes de la segunda guerra mundial, la psicología se propuso tres misiones: llegar a curar la enfermedad mental, contribuir con las personas para el logro de una vida más productiva y satisfactoria, por último identificar y promover el talento. Sin embargo, en la práctica, desconoció dos de las misiones propuestas y optó para su práctica, por un modelo médico hegemónico propio de las ciencias de la salud, organizado desde y hacia la enfermedad.

Hasta mediados del siglo XX la salud se distinguió por su concepción biologicista, por tanto a partir de la enfermedad, evidenciándose en conceptualizaciones presentadas por entes rectores de la salud a nivel mundial, encontrando dicha situación serios cuestionamientos, como el presentado por Ramos en 2003 quien sostiene que la definición aportada por la Organización Mundial de la Salud (OMS) es una de las definiciones más antiguas y en total desuso, evidenciando dos claros inconvenientes: identificar la salud con la ausencia de 
la enfermedad y no permitir estados intermedios, pues sólo reconoce sujetos enfermos o sanos (Ramos, 2012). Sin embargo, al considerar que el concepto de salud es histórico, dinámico y va modificándose en relación con la época y a las condiciones ambientales en las que nos encontramos (Valenzuela, 2016), comprobaremos en la actualidad, un mejor escenario para las ciencias que vinculen a este ámbito, al considerar nuevos elementos como la promoción que no busca solo enfrentar la enfermedad, sino también incrementar la salud y el bienestar en general (Godoy, 1999).

En este panorama la psicología positiva establece su práctica bajo el llamado enfoque salugénico, generando de esta manera una brecha cada vez más profunda entre la práctica psicológica y los llamados enfoques médicos. Es así como se asume la importancia de comprender que la psicología es también el estudio de las fortalezas y virtudes de las personas, para lo cual se deberían establecer procedimientos perfectibles de abordaje, garantizando el bienestar y desarrollo sostenible del potencial y talento humano en distintos escenarios que, por sus características, se hagan idóneos a dicha al desarrollo de ciertas prácticas. Dentro del cúmulo de esfuerzo vinculados a este fin, vemos que Seligman tuvo la virtud de identificar tendencias, anteriormente colocadas en segundo plano y con el uso de procedimientos de orden científico, organizar un reciente cúmulo de conocimientos en modelos de interpretación teórica y estructura programática, encontrando en este camino, el interés de la comunidad científica así como la posibilidad de ahondar en estudio y garantizar la difusión a la sociedad en general de descubrimientos propios del naciente enfoque (Linley, Joseph, Harrington, \& Wood, 2006).

Llegado a este punto, a fin de establecer un panorama articulado para el análisis, se hace necesaria la conceptualización de la psicología positiva para lo cual nos remitimos a lo establecido por dos de sus más grandes exponentes, quienes entienden el campo de la psicología positiva, en un nivel subjetivo que refiere a las experiencias subjetivas tales como: bienestar, alegría y satisfacción (en el pasado); esperanza y optimismo (para el futuro); además de fluir - flow- y felicidad (en el presente). A nivel individual, se refiere a los rasgos individuales positivos: capacidad de amar, vocación, perseverancia, perdón, originalidad, visión de futuro, espiritualidad, talento y sabiduría. A un nivel grupal, hace referencia a las virtudes cívicas y las instituciones: responsabilidad, altruismo, moderación, tolerancia, ética"(Seligman \& Csikszentmihalyi, 2000). Una vez analizada la complejidad y amplitud del campo abordado y de las variables implícitas en el estudio, podríamos llegar a definir la psicología positiva como el enfoque de la psicología que busca comprender y facilitar la felicidad y el bienestar subjetivo (como se citó en Carr, 2007).

Siguiendo lo ya mencionado ,Seligman, en 2002, planteó que existen tres vías de acceso para una vida plena: las emociones positivas (como parte de una propuesta hedonista), que se alcanza mediante el savoring y mindfullness, como segunda vía encontraríamos al compromiso con la tarea y la capacidad de experimentar (haciendo que el individuo se encuentre ensimismado en la tarea, en un estado de flujo donde la actividad absorbe al sujeto, con escaza percepción del tiempo), por último encontramos a la búsqueda de sentido, que solo podría ser entendida en un contexto global más amplio, es decir, no se limitaría a una práctica concreta de algún tipo, sino por el contrario al desarrollo armónico y dinámico de la vida en su conjunto.

Como se puede llegar a entender, la psicología positiva se establece bajo la negación de la falta o ausencia de algo, situación claramente contradictoria al enfoque biologicista, donde se hace necesario superar la falta de salud, mediante el diagnóstico y tratamiento de la enfermedad, siendo lo importante bajo el enfoque positivo, el llegar a potenciar las cualidades o características innatas del individuo, las mismas que en la práctica le permitan ampliar posibilidades en entornos altamente competitivos. Es importante a su vez, comprender en el presente contexto, que el aporte de la psicología dentro del campo de la salud, no es a ningún entender poco fructífero, siendo muestra objetiva del trabajo ejecutado, el conjunto de manuales vinculados al diagnóstico y entendimiento de la patología, así como al importante número de procedimientos estandarizados vinculados a la atención de trastornos y demás problemáticas propios de este campo del saber. Por lo tanto, la psicología positiva no pretende limitar el ámbito de ejercicio de la psicología en salud sino, por el contrario, ampliar el horizonte de intervención del profesional psicólogo al campo de la normalidad, entendida como condición básica y común del individuo, implementando a partir de su conocimiento distintas estrategias a fin de impulsar su potencial y en la práctica buscar un estado de plenitud con la vida, articulado a incrementos en los niveles de felicidad, conociendo además, que la felicidad trae consigo beneficios, que en muchos aspectos van de la mano con sentirse saludable, exitoso y conllevan a un mayor compromiso social (Lyubomirsky, King, \& Diener, 2005)

En el Perú, el interés por la psicología positiva es reciente, sin embargo vemos que al igual que en otros países siempre se desarrollaron esfuerzos por comprender la felicidad y los estados de bienestar de las personas, llegándose incluso a sustentar el desarrollo de civilizaciones antiguas como esencialmente felices, así como asociando a sus representantes con ideales de justicia, que dan paso al imaginario colectivo para la defensa de un régimen de felicidad en el tiempo de los Incas (Roy, 2017), además existe mucho dentro de la cosmovisión andina y su complejidad, que sería importante analizar para entender desde una óptica experiencial la felicidad y sus concomitantes en nuestro país, sin embargo el presente artículo no aspira un acercamiento a estos aspectos, sin por ello dejar de considerar su relevancia. Se debe considerar, en tiempos recientes, un importante aporte en nuestro país dentro del estudio científico de la felicidad, desde la óptica psicológica, el desarrollo de una escala factorial para medir la felicidad, presentada por Alarcon, en 2006, instrumento de 27 items, que identifica mediante análisis factorial cuatro componentes como: sentido positivo de la vida, satisfacción 
con la vida, realización personal y alegría de vivir; se constituye en un claro aporte, debiendo analizarse como un emprendimiento que hace objetivo el análisis de la felicidad, el bienestar y por añadidura de la psicología positiva.

\section{Conclusión}

En razón a lo analizado se entiende que la psicología positiva no es únicamente un movimiento espiritual o de autoayuda, sino se constituye en un alcance científico con verificación empírica para el logro del bienestar y la calidad de vida. En la actualidad presenta una serie de experiencias claramente documentadas que lejos de analizarse superficialmente podrían en relación con sustentos adecuados coadyuvar al desarrollo de procedimientos y prácticas a favor de las personas.

La psicología positiva supera el énfasis en la patología, dado por la psicología desde los años 60, permitiendo la configuración de una visión prospectiva más realista en la práctica de la psicología, la misma que no se encuentre parapetada por la dualidad salud enfermedad. Dicha nueva configuración de este campo del saber, permite acoger nuevos aportes que obedecen a criterios de orden científicos los cuales se presentan como relevantes en los distintos contextos.

\section{Bibliografía}

Alarcon, R. (2006). Desarrollo de una Escala Factorial para Medir la Felicidad. Revista Interamericana de Psicología, 99-106. Caparros, A. (1978). La psicología ciencia multiparadigmática. Anuario de Psicología , 19, 79-110.

Carr, A. (2007). Psicología positiva: la ciencia de la felicidad. Barcelona: Paidos.

Godoy, J. (1999). Psicología de la salud: delimitación conceptual. En M. Símon, Manual de psicoloigía de la salud: fundamentos, metodología y aplicaciones (págs. 39-65). Madrid: Biblioteca nueva.

Linley, A., Joseph, A., Harrington, S., \& Wood, A. (2006). Positive psychology: Past, present and (possible) future. The Journal of Positive Psychology, 1 (1), 3-16.

Lupano, M., \& Castro, A. (2010). Psicologìa positiva: análisis desde su surgimiento. Ciencias Psicológicas , I, 43-56.

Lyubomirsky, S., King, L., \& Diener, E. (2005). The benefits of frequent positive affect: Does happiness lead to success? Psychological Bulletin, 803-855.

Ramos, A. (2012). Actividad física e higiene para la salud. Las Palmas de Gran Canaria: Universidad de las Palmas .

Roy, H. (2017). El Inca y su refugio mítico: espacio de regeneración y resistencia. Diálogo Andino , 103-111.

Seligman, M. (2002). La autentica felicidad. Barcelona: Vergara .

Seligman, M., \& Csikszentmihalyi, M. (2000). Positive psychology: An introduction. American Psychologist, 5-14.

Valenzuela, L. (2016). La salud, desde una perspectiva integral. Revista Universitaria de la Educación Física y el Deporte , 50-59.
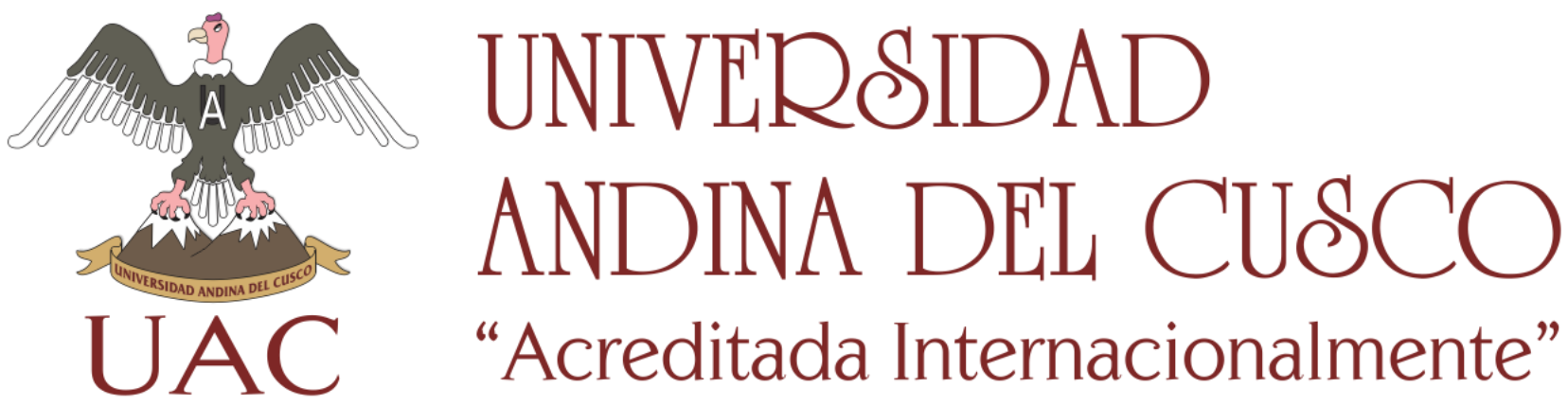

Rev. Yachay volumen (7) Número (1), enero-diciembre 2018 